\title{
Hepatic structural alteration in adult programmed offspring (severe maternal protein restriction) is aggravated by post-weaning high-fat diet
}

\author{
Vanessa Souza-Mello, Carlos A. Mandarim-de-Lacerda and Márcia B. Aguila* \\ Laboratory of Morphometry and Cardiovascular Morphology, Biomedical Center, Institute of Biology, State University \\ of Rio de Janeiro, Av. 28 de Setembro 87 (fds), 20551-030 Rio de Janeiro, RJ, Brazil \\ (Received 4 January 2006 - Revised 25 April 2007 - Accepted 27 April 2007)
}

The present study aimed to evaluate the effects of a post-weaning high-fat (HF) diet upon hepatic morphology in rats subjected to perinatal protein restriction. Pregnant Wistar rats were assigned to a normal-protein diet (NP; with $19 \%$ of protein) or a low-protein (LP) diet (with $5 \%$ of protein). At weaning, the following groups were formed: NP and NP-HF, males and females, which were fed standard chow and an HF diet, respectively. Likewise, LP rat dams originated LP and LP-HF offspring, both sexes. Euthanasia was performed at 6 months of age. Three-way ANOVA disclosed a three-factor interaction among sex, perinatal diet and HF diet in relation to body mass, retroperitoneal fat pad, liver mass:tibia length ratio, binucleation rate and hepatocyte area at 6 months old $(P<0 \cdot 05)$. The high-fat diet intensified the effects of perinatal protein restriction concerning systolic blood pressure, genital fat pad and hepatocyte number $(P<0 \cdot 05$; two-way ANOVA). Furthermore, higher steatosis rates and insulin and leptin concentrations were found in males fed on the HF diet, indicating a sex-post-weaning diet interaction $(P<0 \cdot 05$; two-way ANOVA). Fetal programming and $\mathrm{HF}$ diet as a single stimulus caused mild hypertension at 3 months, an important reduction in hepatocyte number as well as stage 1 steatosis at 6 months. However, hypertension and hepatocyte number deficit were worsened and grade 2 steatosis occurred after exposure to the HF diet. All of these serve to highlight the paramount importance of intra-uterine conditions and postnatal diet quality when it comes to the pathogenesis of chronic diseases.

Non-alcoholic liver steatosis: Metabolic programming: High-fat diet: Stereology

Exposure to undernutrition throughout pregnancy and lactation can influence the offspring's metabolism and increase the susceptibility of man and animals to major diseases in adult life ${ }^{1}$. The immediate outcomes of the adaptive responses are favourable, ensuring immediate survival of the animal in a less than optimal fetal environment and these effects appear to be organ-selective and sex-dependent ${ }^{2}$. Moreover, convincing evidence suggests that programmed offspring show a thrifty phenotype, characterised by an enhanced uptake and storage of nutrients. These developmental adaptations are advantageous as long as nutritional constraints continue in postnatal life. In contrast, if food supply meets or surpasses the recommendation, this excess may be accumulated as fat and therefore metabolic outcomes of fetal programming can be maximised $^{3,4}$. In this context, a high-fat (HF) diet has been proved to amplify body-weight gain in programmed offspring 5 .

With reference to the effects on the key organs, the liver seems to be one of the most impaired by fetal growth retardation $^{2}$. As evidence of this, programmed offspring exhibit fewer but larger hepatic lobules and enzymic alterations, which, combined with a decreased pancreatic $\beta$-cell mass, lead to an insulin-resistant state ${ }^{6,7}$. Meanwhile, HF diets play a crucial role in disrupting the adipoinsular axis, which, in turn, aggravates insulin resistance and increases lipolysis and insulin secretion ${ }^{8-10}$. The former causes an overload of NEFA to the liver and the latter inhibits hepatic NEFA oxidation. Both conditions contribute to a hepatic input of fatty acids (either uptake or lipogenesis) that exceeds its own output (degradation or export), favouring the occurrence of fatty liver or hepatic steatosis ${ }^{1,12}$.

A close relationship between fatty liver and the metabolic syndrome has been well documented, as both of them exhibit insulin resistance as a common pathway ${ }^{13,14}$. Regardless of overweight, abdominal fat and insulin resistance are the most significant risk factors for non-alcoholic fatty liver disease, both of which are magnified by an HF diet. Thus, despite being frequently associated with a wide range of metabolic disorders, dietary fat intake is of paramount importance when it comes to fat accumulation within hepatocytes ${ }^{15}$. Not only does excessive dietary fat increase hepatic fatty acid input, but it also decreases output indirectly by worsening hyperinsulinaemia. Consequently, animal studies focusing on the effects of HF diets upon liver structure may provide new insights into the pathogenesis of the metabolic syndrome, which has been regarded as a major public health concern worldwide ${ }^{11,12}$. Moreover, the amplification of metabolic abnormalities in the offspring of undernourished dams by an 
HF diet suggests that environmental factors are important accelerators in the aetiology of adult-onset disease.

The present study was designed to investigate the hypothesis that a maternal low-protein (LP) diet would alter hepatic structure and function in the offspring. Furthermore, we also examined the influence of a post-weaning HF diet, given the present study's data linking early postnatal HF diet with amplification of the outcomes stemmed from metabolic programming.

\section{Experimental methods}

\section{Animals and diet}

All animal studies were performed according to the guidelines of the animal ethics committee of the State University of Rio de Janeiro (Rio de Janeiro, Brazil). All procedures were carried out in accordance with conventional guidelines for experimentation with animals (NIH publication no. 85-23, revised 1996) and the experimental protocols were approved by the local committee.

Wistar rats bred in our laboratory were maintained under controlled conditions $\left(21 \pm 2^{\circ} \mathrm{C}\right.$, humidity $60 \pm 10 \%, 12 \mathrm{~h}$ dark-12 h light cycle and an air-replacement cycle) with free access to food and water. Virgin females were caged with males overnight, and mating was confirmed the next morning by the presence of a vaginal plug or spermatozoa after a vaginal smear. Dams were then housed individually and fed throughout gestation and the first $10 \mathrm{~d}$ of lactation with one of two diets: a normal-protein (NP) diet (19 $\mathrm{g}$ protein $/ 100 \mathrm{~g}$ diet), or an LP diet $(5 \mathrm{~g}$ protein $/ 100 \mathrm{~g}$ diet $)$.

A severe protein restriction was adopted because we aimed to evaluate programming alterations in both sexes and it is known that modest protein restriction affects male pups exclusively ${ }^{16}$. Both diets were isoenergetic $(1900 \mathrm{~kJ} / 100 \mathrm{~g}$ diet; the LP diet was compensated by the addition of carbohydrates). It is a normal approach to compensate the deficit of protein by carbohydrate in LP diets because the sort of carbohydrate used (complex carbohydrate) will not have an impact upon the endpoints analysed. Furthermore, it is a better option than substitute for lipids as this could turn the diet into an HF one, which has similar effects to protein restriction and could be considered as another model of programming ${ }^{17,18}$. The mineral and vitamin contents in the two diets were identical and in accordance with the American Institute of Nutrition's recommendation (AIN-93G) ${ }^{19}$.

Diets were produced by Rhoster (Rhoster, Sao Paulo, Brazil) and their composition is described in Table 1. Food intake and maternal body weights were recorded daily. As soon as delivery occurred, litters were adjusted to six animals in order to assure adequate and standardised nutrition until weaning ${ }^{20}$. These animals were accompanied until weaning when only one pup per litter was randomly assigned to form the groups of study ${ }^{21}$. It is important to state that the LP diet did not have an impact upon reproductive success as no differences were observed regarding number of dams giving birth, survival of pups or litter size. Within $24 \mathrm{~h}$ after delivery, pups' birth weights were obtained. Offspring sex was identified by the anus-genital distance examination, and thus males and females were weighed separately. To put it more simply, the offspring from the NP diet mother group
Table 1. Composition of isoenergetic perinatal diets

\begin{tabular}{|c|c|c|}
\hline \multirow[b]{2}{*}{ Nutrients $(\mathrm{g} / 100 \mathrm{~g})$} & \multicolumn{2}{|c|}{ Perinatal diet } \\
\hline & NP & LP \\
\hline \multicolumn{3}{|l|}{ Carbohydrates } \\
\hline Maize starch & 33.5 & $47 \cdot 65$ \\
\hline Sucrose & $20 \cdot 0$ & $20 \cdot 0$ \\
\hline Casein & $19 \cdot 0$ & $5 \cdot 0$ \\
\hline Cystine & 0.3 & 0.15 \\
\hline Choline & $0 \cdot 2$ & 0.2 \\
\hline Fat (soyabean oil) & $16 \cdot 0$ & $16 \cdot 0$ \\
\hline Fibre (cellulose) & $5 \cdot 0$ & $5 \cdot 0$ \\
\hline Mineral mix (AIN-93G) ${ }^{\star}$ & $1 \cdot 0$ & $1 \cdot 0$ \\
\hline Vitamin mix (AIN-93G)* & $5 \cdot 0$ & $5 \cdot 0$ \\
\hline Energy (kJ/100 g diet) & 1900 & 1900 \\
\hline
\end{tabular}

was termed NP and those from the LP diet mother group were termed LP.

The respective diets were maintained until half way through lactation in order to cover the whole period of organogenesis in rodents ${ }^{22}$. At postnatal day 10, and hence during the remaining lactation period, dams were fed the standard rat chow (SC). At weaning (at age $21 \mathrm{~d}$ ), female and male offspring from NP and LP dams were randomly divided into two balanced postnatal groups to be fed on an SC (6g fat/ $100 \mathrm{~g}$ diet; $1800 \mathrm{~kJ} / 100 \mathrm{~g}$ diet $)$ or an $\mathrm{HF}$ diet $(30 \mathrm{~g}$ fat $/ 100 \mathrm{~g}$ diet; $2300 \mathrm{~kJ} / 100 \mathrm{~g} \mathrm{diet})^{23}$ (Table 2). Each rat was labelled, weighed and measured weekly for up to 6 months of age.

\section{Body mass and food intake}

Body mass was measured every week (Friday; 08.00 hours) and food intake of all offspring was measured daily (08.00 hours). Fresh diet was provided daily and any remaining diet from the previous day was discarded.

Table 2. Composition of post-weaning diets ( $\mathrm{g} / 100 \mathrm{~g}$ )

\begin{tabular}{lcc}
\hline & \multicolumn{2}{c}{ Post weaning diets } \\
\cline { 2 - 3 } & HF & SC \\
\hline Component & & \\
Commercial rat chow & 60.0 & $100 \cdot 0$ \\
Shorteningt & 25.0 & - \\
Condensed milk $\ddagger$ & 15.0 & - \\
Nutrients & & \\
Protein & 15.0 & 23.0 \\
Fat & 30.0 & 6.0 \\
SFA & 7.1 & 0.9 \\
MUFA & 9.8 & 1.3 \\
PUFA & 5.6 & 3.7 \\
Trans fatty acids & 7.5 & 0.1 \\
Carbohydrate & 55.0 & 71.0 \\
Energy (kJ) & 2300 & 1800 \\
\hline
\end{tabular}

SC, standard chow; HF, high-fat.

* Nuvital, Nuvilab, Colombo PR, Brazil.

†Primor, Santa Catarina SC, Brazil.

$\ddagger$ Nestlé, Sao Paulo SP, Brazil. 


\section{Blood pressure}

Systolic blood pressure (BP) was measured weekly in conscious rats by a non-invasive method (tail-cuff plethysmography; Letica LE 5100; Panlab, Barcelona, Spain) from age 3 to 6 months. Animals went through a 2-week period of adaptation before the beginning of the measurement of BP. It is noteworthy to say that animals were manipulated by one individual and were kept in a calm and silent room. Consequently, no restraint was applied to them and stress was minimised as no significant increment in heart rate was observed during the procedure. They were also slightly warmed so as to dilate the caudal artery and make the tail-pulse easier to perceive. Three measurements were taken per animal and the average was used as the official BP in that week.

\section{Blood and tissue sampling}

On the day before euthanasia, animals were kept in metabolism cages and food-deprived overnight. Animals were deeply anaesthetised (intraperitoneal sodium pentobarbital), had their thoraxes opened and then blood samples were rapidly obtained by cardiac acupuncture. Afterwards, the vascular system was perfused with constant pressure $(90 \mathrm{mmHg})$ through a catheter placed in the left ventricle (Minipuls 3; Gilson S.A.S., Villiers le Bel, France) with fixative (freshly prepared formaldehyde $(1.27 \mathrm{~mol} / \mathrm{l})$ in $0.1 \mathrm{M}$-phosphate buffer; $\mathrm{pH} 7 \cdot 2$ ) until animal body rigidity.

Fat deposits (retroperitoneal fat and genital fat masses) were completely removed from both sides of the animal and weighed. The retroperitoneal fat pad was taken as the distinct deposit around each kidney along the lumbar muscles. The genital fat pad (ovarian for females and epididymal for males) included adipose tissue surrounding the ureters, bladder, as well as epididymis, ovaries, oviducts, and uterus. The left tibia was meticulously dissected and tibia length was obtained owing to the fact that different body mass could turn absolute parameters into unreliable data. For that reason, tibia length was used to standardise organ and fat pad masses and allows a comparative study amongst all the groups ${ }^{24}$.

After blood collection, plasma was separated from the blood by centrifugation at room temperature. Blood was centrifuged $(120 \mathrm{~g}$ for $15 \mathrm{~min})$ and stored at $-80^{\circ} \mathrm{C}$ until the blood biochemistry was analysed. All the lipids were extracted by the colorimetric enzymic method. Total cholesterol was determined by the cholesterol esterase-cholesterol oxidase-peroxidase method, TAG were measured using the glycerol phosphate oxidase-peroxidase method. LDL-cholesterol was abundantly precipitated by the addition of phosphotungsten acid in the presence of $\mathrm{Mg}$ ions. After centrifugation the cholesterol concentration in the HDL-cholesterol fraction, which remained in suspension, was determined. Friedewald's formula ${ }^{25}$ was used to calculate LDL-cholesterol. With regard to liver function tests, alanine aminotransferase and aspartate aminotransferase were determined using a colorimetric method (Frankel-Reitman). Alkaline phosphatase and $\gamma$-glutamyl transpeptidase were obtained using the kinetic colorimetric method.

\section{Radioimmunoassay for insulin and leptin}

Plasma insulin concentrations were measured by RIA using a rat insulin RIA kit (RI-13K; Linco Research, St Charles, MO,
USA) and plasma leptin concentrations were measured using a rat leptin RIA kit (RL-83K; Linco Research). All samples were analysed in a double assay, for which the intra-assay CV was $4.1 \%$ for leptin and $1.4 \%$ for insulin.

\section{Liver stereology}

Liver volume was measured by submersion, where the fluid displacement (isotonic saline) due to organ volume (V) was recorded by weighing (W). As the isotonic saline specific density (d) is 1.0048 the respective volumes were obtained by $\mathrm{V}_{\text {organ }}\left(\mathrm{cm}^{3}\right)=\mathrm{W}(\mathrm{g}) / \mathrm{d}$ or simply $\mathrm{V}\left(10^{3} \mathrm{~cm}^{3}\right) \cong \mathrm{W}(\mathrm{g})^{26}$. Then, the liver was sliced into several minor fragments and kept for $48 \mathrm{~h}$ at room temperature in the same fixative. Random fragments were embedded in Paraplast plus (SigmaAldrich Co., St Louis, MO, USA), sectioned at 3 and $10 \mu \mathrm{m}$, and then stained with haematoxylin-eosin and picro-sirius red. Several slices were cut per fragment and five microscopic fields per animal were analysed at random. It is important to highlight that an utterly blind analysis was pursued.

A video-microscopic system (Leica DMRBE microscope with planachromatic objectives; Leica, Wetzlar, Germany) and a test system made up of thirty-six test points $\left(\mathrm{P}_{\mathrm{T}}\right)$ were used for the analysis ${ }^{15}$. The volume density (Vv) was estimated by point counting for hepatocytes and steatosis: $\mathrm{VV}_{\text {structure }}=\mathrm{P}_{\mathrm{Pstructure}} / \mathrm{P}_{\mathrm{T}}$, where $\mathrm{P}_{\mathrm{P}}$ is the number of points that hit the structure and $\mathrm{P}_{\mathrm{T}}$ is the total test points. The "disector' method was used to estimate the number of hepatocyte nuclei (hn) in a three-dimensional probe that samples structures proportional to their number without regard to the size or shape of the structures ${ }^{27}$. Two parallel sections were used to create a sampling volume with an upper reference section and a lower section (look down plane), both containing a test frame. Sections were viewed with a $100 \times$ planachromatic immersion oil objective (numerical aperture (NA) $=1.25)$ to identify hn. The thickness (t) of the disector - distance between the two parallel sections - was defined as onequarter to one-third of the height of the hn. For each disector pair, the thickness was verified through an auto-focus device and read-out (the microscope was equipped with a $\mathrm{z}$-axis motorised focus controller microcator with a resolution of $0.1 \mu \mathrm{m})$. The disector method is depicted in Figs. 1 (a) and (b).

The numerical density $(\mathrm{Nv})$ of hn (number of hn per $\mathrm{mm}^{3}$ ) was determined from ten random disector pairs for each animal, being defined as $\mathrm{Nv}_{\mathrm{hn}}=\mathrm{Q}_{\mathrm{hn}}^{-} / \mathrm{t} \times \mathrm{A}_{\mathrm{T}}$, were $\mathrm{Q}^{-}$represents the number of profiles of $h n$ counted in the test frame on the reference section. The total number of hepatocytes in the liver $\left(\mathrm{N}_{\mathrm{h}}\right)$ was estimated as the product of $\mathrm{Nv}_{\mathrm{hn}}$ and the liver volume measured previously corrected by the binucleation rate of hepatocytes.

\section{Data analysis}

Data are shown as means and standard deviations. Statistical analysis was performed by three-way $(2 \times 2 \times 2$ factorial $)$ ANOVA taking interactions between effects (sex, and perinatal and postnatal diets) into account through data analysis software (Statistica, version 6; StatSoft Inc., Tulsa, OK, USA). Thereby, we examined overall significance of a three-way effect and key two-way interactions (sex-perinatal diet, 

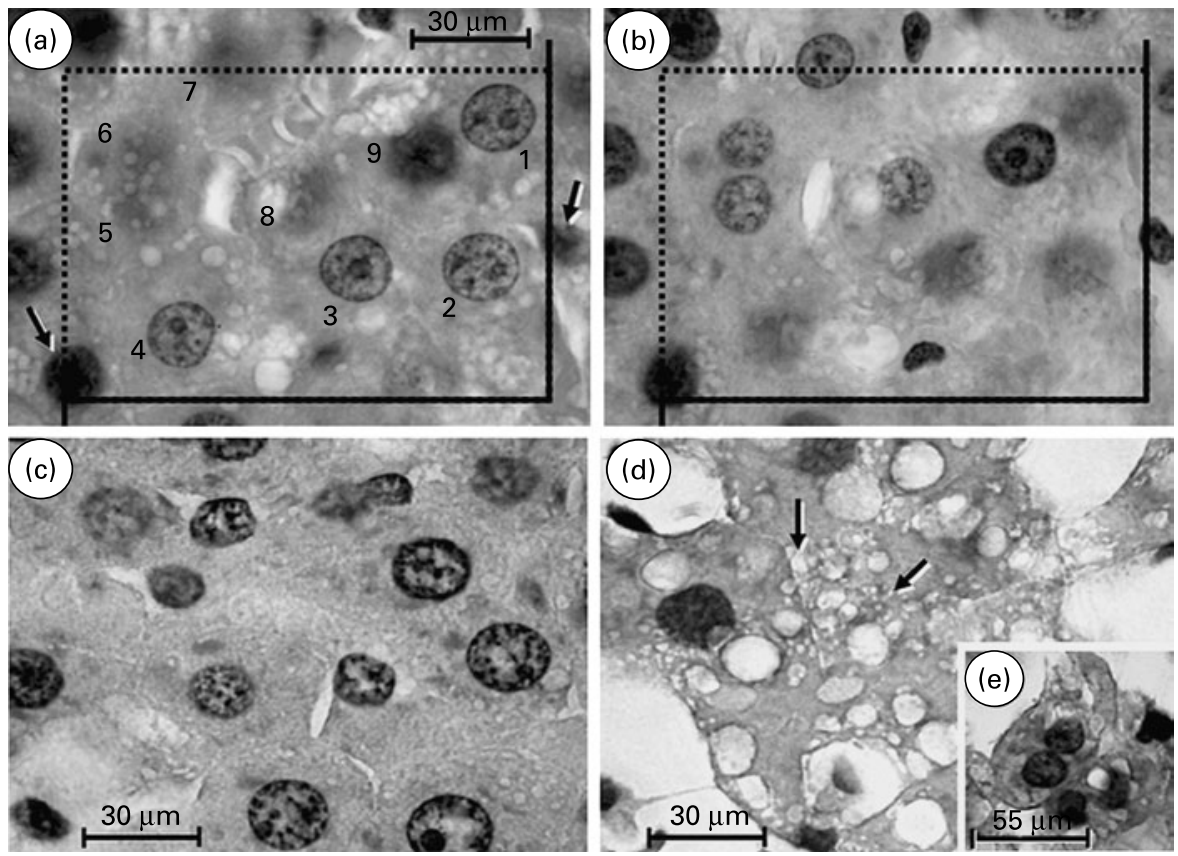

Fig. 1. Photomicrographs of the liver (haematoxylin and eosin stain). Figs. (a) and (b) show the two planes of the 'disector' in the liver. In the upper plane (a) we observed two nuclei crossing the 'forbidden line' $(\downarrow)$, which were excluded. Nine other different hepatocyte nuclei in the frame were considered. In the upper plane only hepatocyte nuclei numbers 1 to 4 showed sharp edges while the nuclei numbers 5 to 9 were shadows. In the down plane (b) hepatocyte nuclei numbers 5 to 9 showed sharp edges while the nuclei numbers 1 to 4 became shadows. We counted only the nuclei showing sharp edges in the reference plane. The normal appearance in the normal-protein-standard chow group is shown in (c), and macro- and microvesicular steatosis ( $\downarrow$ ) in the low-protein-high-fat chow group in (d). Many fields of all groups showed hepatocytes with more than one nucleus (e).

sex-post-weaning diet and perinatal-post-weaning diet). One-way ANOVA was followed by Tukey's post hoc test. A $P$ value of 0.05 was considered statistically significant.

\section{Results}

All the animals tolerated the HF diet, without developing diarrhoea or other physical constraint and did not show significant differences in relation to quantitative food intake.

\section{Biometry}

At birth, LP pups showed a lower body mass (-23\%; $P<0.01$; one-way ANOVA) and a smaller naso-anal length (NAL) $(-5 \%$; $P<0.01$; one-way ANOVA) than NP pups. LP males were more affected than females, indicating an interaction between perinatal diet and $\operatorname{sex}(P<0.02$; two way ANOVA). This difference was maintained until weaning, when it became even more apparent $(-27$ and $-12 \%$; $P<0.0001$ respectively; one-way ANOVA). However, at age 4 weeks, this underweight was overcome in LP-SC groups. The NAL of LP-SC females reached that of the NP-SC group at age 5 weeks, whereas in males it happened only at age 7 weeks. With regard to the effects of the HF diet, it provoked overweight in both male $(+10 \% ; P<0.05$; one-way ANOVA) and female ( $+25 \% ; P<0.01$; one-way ANOVA) NP-HF groups at age 11 weeks (after 8 weeks of the HF diet). In spite of this, the LP-HF groups showed sexual dimorphism concerning this outcome. At age 18 weeks, the female LP-HF rats developed a significant overweight compared with the LP-SC group $(+21 \% ; P<0.01$; one-way
ANOVA), while males recuperated their body mass but did not differ significantly from the LP-SC group until euthanasia. At age 6 months, the post-weaning diet enhanced the effects of the perinatal diet $(P<0.001$; two-way ANOVA) and then the LP-HF groups showed higher body masses than the LP-SC groups. In this way, ANOVA disclosed a significant threefactor interaction among sex, and perinatal and post-weaning diets, females being more affected than males $(P<0.03$; three-way ANOVA). All the results related to body mass are summarised in Table 3.

As far as BP is concerned, maternal severe protein restriction triggered mild hypertension in both males $(+20 \%$; $P<0.001$; one-way ANOVA) and females $(+20 \%$; $P<0.001$; one-way ANOVA) of the LP-SC groups by age 3 months, with this difference maintained until euthanasia. Furthermore, as an isolated effect, the post-weaning HF diet also showed efficacy in causing hypertension by age 3 months in both sexes of the NP-HF group (+20\%; $P<0.01$; one-way ANOVA). These isolated effects caused by maternal undernutrition and an adverse post-weaning environment were maximised when both stimuli were applied simultaneously, showing an interaction between perinatal and post-weaning diets $(P<0.00001$; two-way ANOVA). Consequently, the LP-HF groups showed the most pronounced BP values throughout the whole experiment, reaching values $11 \%$ higher than the LP-SC group $(P<0.001$; one-way ANOVA) among females and $15 \%$ higher than the LP-SC group $(P<0.001$; one-way ANOVA, $)$ among males at age 6 months (Fig. 2).

Considering the amount of fat pads as a percentage of body mass, animals fed the HF diet showed a greater quantity of 
Table 3. Biometrical and stereological datall

(Mean values and standard deviations)

\begin{tabular}{|c|c|c|c|c|c|c|c|c|c|c|c|c|c|c|}
\hline \multirow[b]{2}{*}{ Groups } & \multicolumn{2}{|c|}{ BM (g) } & \multicolumn{2}{|c|}{ LM:TL (g/cm) } & \multicolumn{2}{|c|}{ GFP:BM (\%) } & \multicolumn{2}{|c|}{ RFP:BM (\%) } & \multicolumn{2}{|c|}{$\begin{array}{l}\text { No. of hepato- } \\
\text { cytes (billion) }\end{array}$} & \multicolumn{2}{|c|}{ Leptin (ng/ml) } & \multicolumn{2}{|c|}{ Insulin (pmol/l) } \\
\hline & Mean & SD & Mean & SD & Mean & SD & Mean & SD & Mean & SD & Mean & SD & Mean & SD \\
\hline \multicolumn{15}{|l|}{ Females } \\
\hline NP-SC $(n 8)$ & $230^{*}$ & 24 & 1.7 & 0.2 & $2 \cdot 7$ & 0.7 & 1.3 & 0.5 & $51 \cdot 6^{*}$ & $10 \cdot 6$ & 1.8 & 0.2 & $46 \cdot 7$ & $20 \cdot 2$ \\
\hline NP-HF $(n 6)$ & $328^{*} \dagger$ & 61 & $2.4 \dagger$ & 0.4 & $7 \cdot 0^{*} \dagger$ & 0.9 & $3.8^{*} \dagger$ & $1 \cdot 2$ & $41 \cdot 1$ & $11 \cdot 7$ & $3 \cdot 0^{*} \dagger$ & 0.6 & $93 \cdot 3$ & 44.0 \\
\hline LP-SC $(n 8)$ & $209^{*}$ & 23 & 1.7 & 0.3 & $2 \cdot 0$ & 0.8 & 0.7 & 0.2 & $33 \cdot 2^{*} \dagger$ & 7.5 & $2 \cdot 0$ & 0.5 & $62 \cdot 2$ & $10 \cdot 1$ \\
\hline LP-HF $(n 9)$ & $305^{\star}+\S$ & 42 & $1.9^{*}$ & 0.7 & $6 \cdot 5^{*}+\S$ & 1.9 & $3.8+\S$ & 0.5 & $28 \cdot 2$ & 8.0 & $8.8+\S$ & 1.4 & $122 \cdot 5$ & 17.5 \\
\hline \multicolumn{15}{|l|}{ Males } \\
\hline NP-SC $(n 6)$ & 359 & 18 & $2 \cdot 1$ & 0.2 & 1.8 & 0.3 & 1.1 & 0.5 & $72 \cdot 8$ & $12 \cdot 2$ & $2 \cdot 2$ & 0.3 & $180 \cdot 8$ & $72 \cdot 9$ \\
\hline NP-HF $(n 8)$ & $481 \dagger$ & 36 & $2 \cdot 6$ & 0.2 & $4 \cdot 1 \dagger$ & 0.5 & $6.5 \dagger$ & 1.3 & $42 \cdot 2 \dagger$ & $6 \cdot 8$ & $15 \cdot 0 \dagger$ & 1.5 & $437.5 \dagger$ & $76 \cdot 3$ \\
\hline LP-SC $(n 7)$ & 335 & 30 & $2 \cdot 3$ & 0.5 & 1.0 & 0.2 & 0.9 & 0.2 & $56.0 \dagger$ & $11 \cdot 2$ & 2.0 & 0.5 & 116.7 & $66 \cdot 3$ \\
\hline LP-HF $(n 7)$ & $383 \ddagger$ & 22 & $3.2+\S$ & 0.5 & $3.0 \S$ & 0.4 & $4.1 \neq \S$ & 1.0 & $36 \cdot 8 \S$ & $2 \cdot 8$ & $13 \cdot 2 \S$ & $2 \cdot 6$ & $478.3 \S$ & $119 \cdot 1$ \\
\hline
\end{tabular}

BM, body mass; LM, liver mass; TL, tibia length; GFP, genital fat pad; RFP, retroperitoneal fat pad; NP, normal-protein; SC, standard chow; HF, high-fat; LP, low-protein.

${ }^{*}$ Mean value was significantly different from that of the matched male group $(P<0.05)$.

t Mean value was significantly different from that of the same-sex NP-SC group $(P<0.05)$

$\ddagger$ Mean value was significantly different from that of the same-sex NP-HF group $(P<0.05)$.

$\S$ Mean value was significantly different from that of the same-sex LP-SC group $(P<0.05)$

$\|$ Two-way ANOVA disclosed significant interactions between sex and perinatal diet $(P<0.01$ for LM:TL; $P<0.01$ for RFP:BM), sex and postnatal diet $(P<0.02$ for GFP:BM $P<0.0001$ for RFP:BM; $P<0.02$ for number of hepatocytes; $P<0.03$ for leptin; $P<0.001$ for insulin) and perinatal and postnatal diet $(P<0.001$ for BM; $P<0.01$ for GFP; $P<0.0001$ for RFP:BM; $P<0.001$ for number of hepatocytes). Three-way ANOVA disclosed interactions between sex, perinatal and postnatal diets concerning BM $(P<0.03)$, LM:TL $(P<0.04)$ and RFP:BM $(P<0.001)$.

retroperitoneal fat pad than their respective SC group. Male NP-HF animals showed eight times as much as the amount of fat that NP-SC animals accumulated in this site, whereas females showed the quadruple of their controls' amount $(P<0.0001$; one-way ANOVA). Although female NP-HF and LP-HF animals did not show any significant difference between their values, NP-HF males showed a larger retroperitoneal fat accumulation than LP-HF males $(+50 \%$; $P<0.0001$; one-way ANOVA). An interaction among sex, and perinatal and post-weaning diets took place regarding this parameter $(P<0.001$; three-way ANOVA). With reference to genital fat pads, both sexes showed strikingly similar

(a)

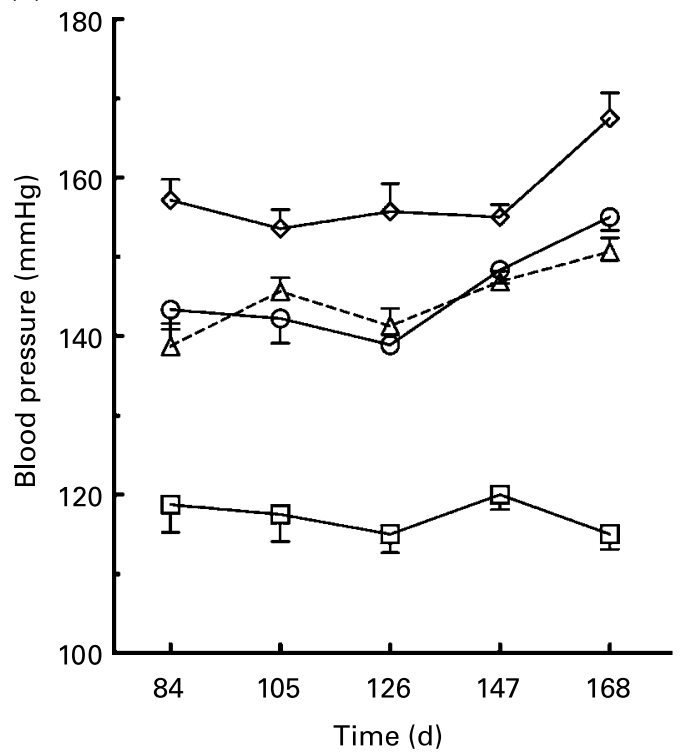

patterns of accumulation. Females fed the HF diet tended to accumulate more fat in this site than males $(+16 \%$ in NPHF females; $P<0.0001 ;+42 \%$ in LP-HF females; $P<0.0001$; one-way ANOVA; Table 3). Interactions were observed between sex and post-weaning diet $(P<0.001$; two-way ANOVA), females being more affected by perinatal and post-weaning diets $(P<0 \cdot 001$; two-way ANOVA), emphasising that the HF diet had additional effects on fetal programming outcomes.

Blood glucose values of males fed the HF diet suppressed their counterparts' values. However, their values were not compatible with diabetes diagnosis (Table 4). In contrast,

(b)

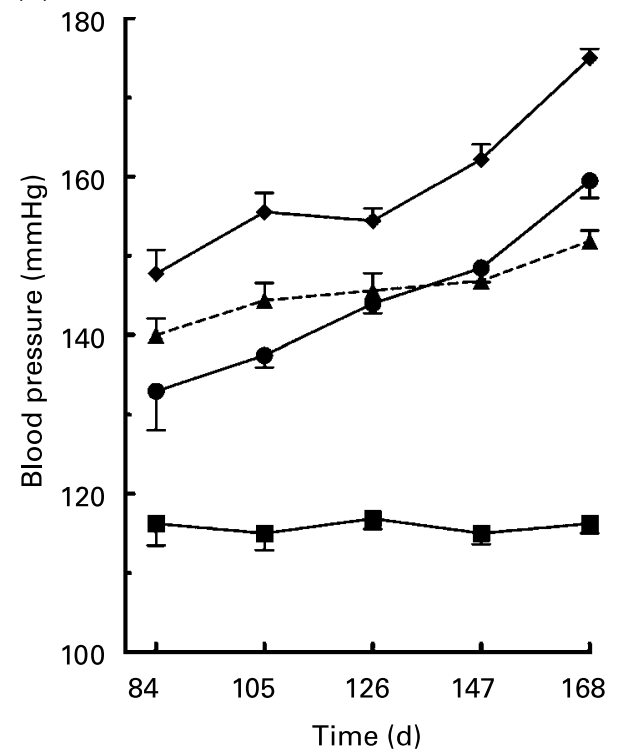

Fig. 2. Systolic blood pressure evolution throughout the experiment in female (a) and male (b) rats. ( $\diamond)$, Low protein (LP)-high-fat chow (HF) female group; $(O)$, normal-protein (NP)-HF female group; $(\Delta)$, LP-standard chow (SC) female group; ( $\square$ ), NP-SC female group; $(\diamond)$, LP-HF male group; $(\bullet)$, NP-HF male group; $(\Lambda)$, LP-SC male group; (ם), NP-SC male group. Values are means, with their standard errors represented by vertical bars. 
females did not show any significant difference amongst the groups. In the same way, lipid profile determination did not provide relevant results. In relation to liver function tests, however, females of the NP-HF group showed higher alkaline phosphatase values when compared with the NP-SC group $(P<0 \cdot 05$; one-way ANOVA) (Table 4$)$.

The increase in fat intake was paralleled by a significant increase in circulating plasma leptin concentrations $(P<0.001$; one-way ANOVA) in the NP-HF and LP-HF groups. However, males presented higher values than females, characterising an interaction between sex and post-weaning diet $(P<0 \cdot 02$; two-way ANOVA). Likewise, insulin concentrations were affected by the HF diet. Males fed on this hyperlipidic diet exhibited hyperinsulinaemia, emphasising a sex-post-weaning interaction $(P<0 \cdot 001$, twoway ANOVA). Values of leptin and insulin are shown in Table 3 .

\section{Stereological analysis}

First, liver mass seemed to be a biased parameter on the grounds that within the same sex, the groups showed significantly different body masses. Therefore, the liver mass:tibia length ratio was used and the results suggested that the HF diet exerted a far bigger influence on liver mass than maternal undernutrition in females, as the NP-HF group showed an increase of $29 \%(P<0.03$; one-way ANOVA). However, in males, the LP-HF group exhibited the highest value $(+28 \%$ in relation to the LP-SC group; $P<0.001$; one-way ANOVA), emphasising an interaction between fetal programming and post-weaning diet and sex regarding this parameter $(P<0.03$; three-way ANOVA).

With reference to the number of hepatocytes (Table 4), it was significantly decreased by perinatal diet (males $-23 \%$; $P<0.05$; females $-35 \% ; P<0.01$; one-way ANOVA) at 6 months old and by post-weaning diet in NP-HF males $(-42 \% ; P<0.0001$; one-way ANOVA). Both effects were additive and there was a statistical perinatal-post-weaning diet interaction $(P<0.001$; two-way ANOVA), suggesting that the programming-induced number of hepatocyte decrease is amplified by the HF diet. Additionally, a post-weaning diet-sex interaction was observed $(P<0.02$; two-way ANOVA). As a result, LP-HF males showed the most reduced number of hepatocytes, overriding LP results $(-34 \%$; $P<0.01$; one-way ANOVA). However, the hepatocyte number:liver mass ratio provided a more elucidative result as NP-HF females were equally affected by the HF diet, showing a significant reduction $(-44 \% ; P<0.05$; one-way ANOVA) when compared with the NP-SC group (Fig. 3).

Steatosis was a commonplace finding in the present study, being present even in NP-SC groups (Figs. 1 (c), 1 (d) and 4 ). Once again, maternal protein restriction programmed a higher percentage of steatosis in LP-SC males $(+62 \%$; $P<0.05$; one-way ANOVA) and LP-SC females (+64\%; $P<0.0001$; one-way ANOVA), as the post-weaning HF diet did in NP-HF males $(+75 \% ; P<0 \cdot 0001$; one-way ANOVA) and in NP-HF females $(+59 \% ; \quad P<0.01$; one-way ANOVA). Although the LP-HF groups showed the highest percentage of steatosis, there was not an interaction between maternal and post-weaning environments. Steatosis rate increased by $57 \%$ in LP-HF males $(P<0.0001)$ when

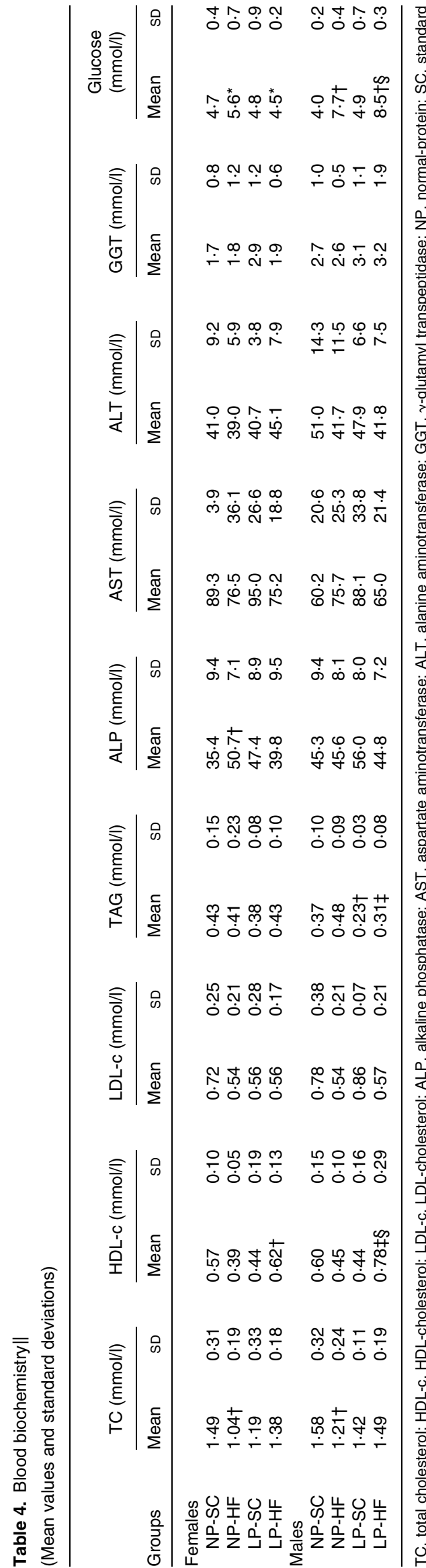

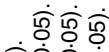

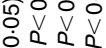

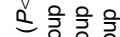

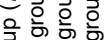

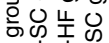

$\frac{\infty}{\pi} \sum^{2}$ 

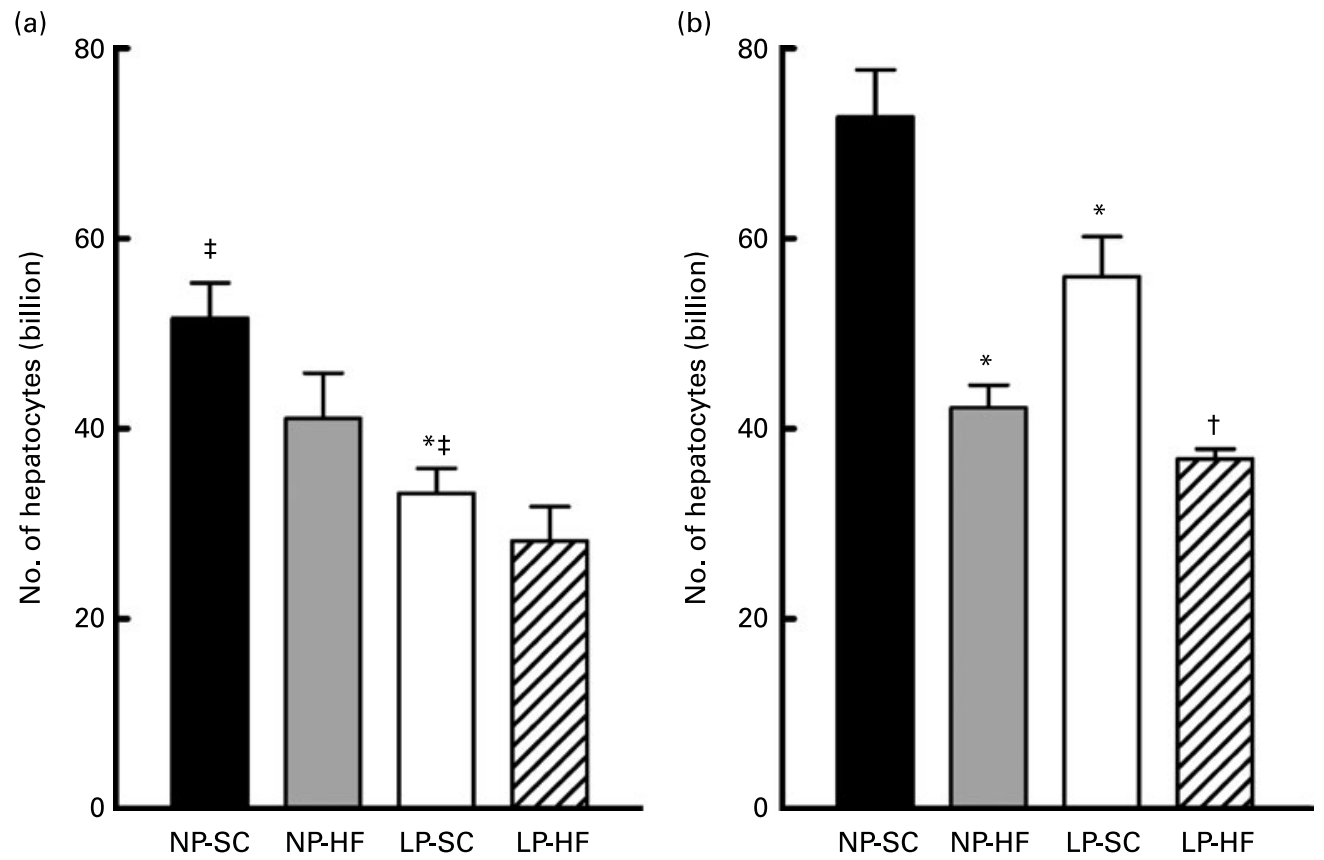

Fig. 3. Number of hepatocytes in female (a) and male (b) rats. Values are means for five rats per group, with their standard errors represented by vertical bars. NP, normal-protein; SC, standard chow; HF, high-fat chow; LP, low-protein. * Mean value was significantly different from that of the same-sex NP-SC group $(P<0.0001)$. $†$ Mean value was significantly different from that of the same-sex LP-SC group $(P<0.0001)$. $\ddagger$ Mean value was significantly different from that of the male-matched group $(P<0.0001)$. Two-way ANOVA disclosed interactions between sex and postnatal diet $(P<0.02)$ and between perinatal diet and postnatal diet $(P<0 \cdot 001)$

compared with the LP-SC group, whereas LP-HF females showed $43 \% \quad(P<0 \cdot 01)$ more steatosis than the LP-SC group, characterising a sex-post-weaning diet interaction $(P<0 \cdot 03$; two-way ANOVA). Two-way ANOVA of binucleation

(a)

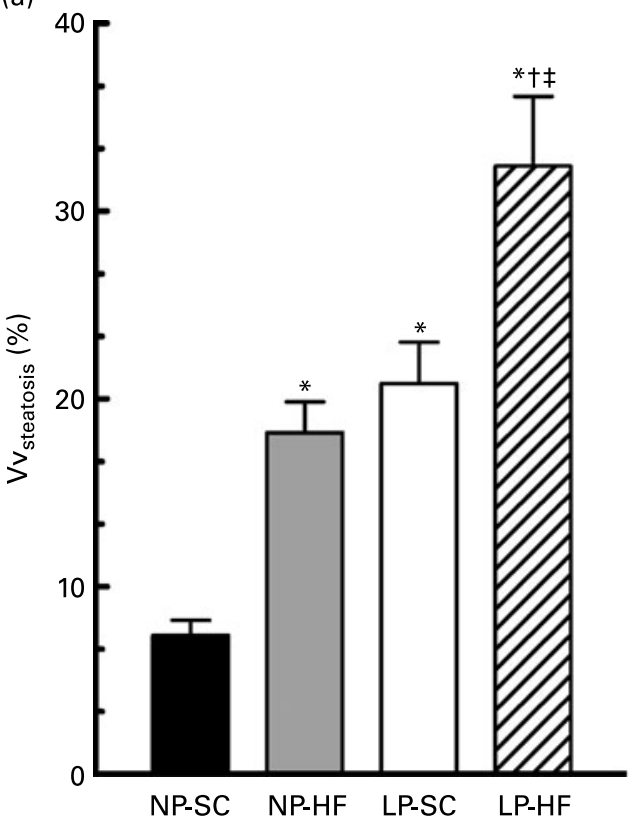

data revealed a significant perinatal-post-weaning diet interaction, suggesting that fetal programming outcomes are intensified by a post-weaning $\mathrm{HF}$ diet $(P<0 \cdot 0001$; three-way ANOVA) (Figs. 1 (e) and 5).

(b)

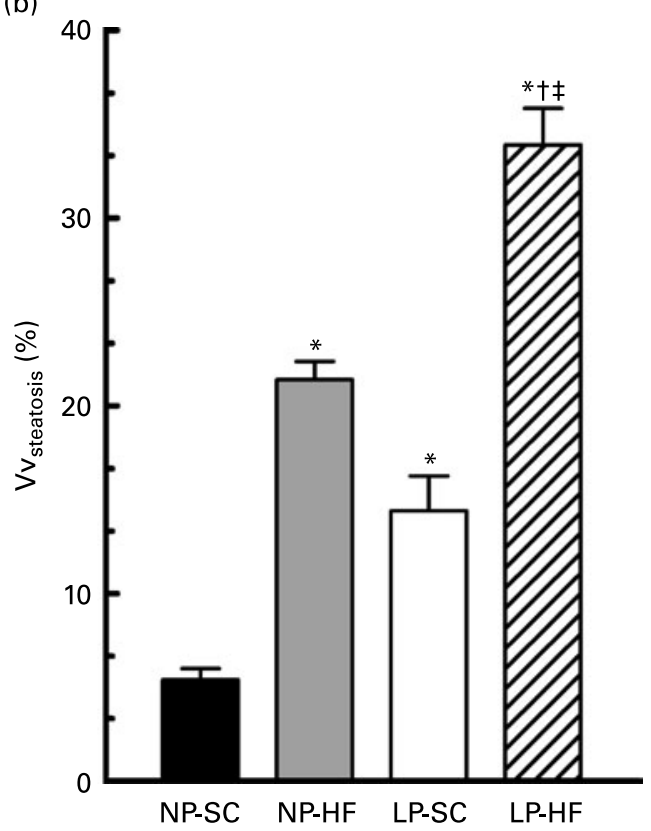

Fig. 4. Volume density of hepatic steatosis $\left(\mathrm{V}_{\mathrm{steatosis}}\right)$ in female $(\mathrm{a})$ and male (b) rats. Values are means for five rats per group, with their standard errors represented by vertical bars. NP, normal-protein; SC, standard chow; HF, high-fat chow; LP, low-protein. * Mean value was significantly different from that of the same-sex NP-SC group $(P<0.0001)$. † Mean value was significantly different from that of the same-sex NP-HF group $(P<0 \cdot 0001)$. $\ddagger$ Mean value was significantly different from that of the same-sex LP-SC group $(P<0.0001)$. Two-way ANOVA disclosed an interaction between sex and postnatal diet $(P<0.03)$. 
(a)

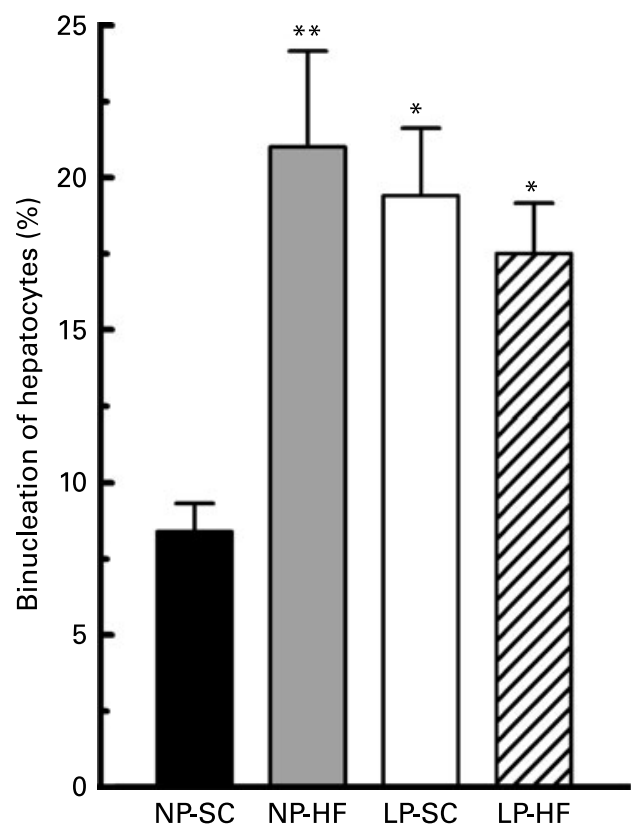

(b)

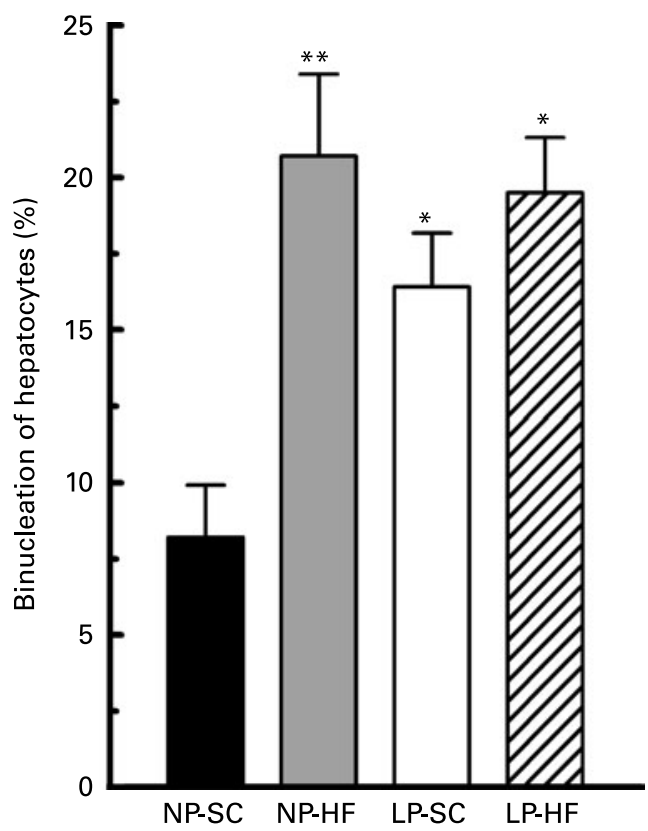

Fig. 5. Binucleation of hepatocytes rate in female (a) and male (b) rats. Values are means for five rats per group, with their standard errors represented by vertical bars. NP, normal-protein; SC, standard chow; HF, high-fat chow; LP, low-protein. Mean value was significantly different from that of the same-sex NP-SC group: ${ }^{*} P<0.01,{ }^{* *} P<0.0001$. Two-way ANOVA disclosed an interaction between perinatal diet and postnatal diet $(P<0.0001)$.

Hepatocyte size was an additional finding that confirmed the greater influence that the HF diet exerts upon the hepatic structure of males when compared with females, indicating a sex-post-weaning diet interaction $(P<0.00001$; two-way ANOVA). A significant increase of hepatocyte area was shown by NP-HF males $(+44 \% ; P<0.01)$ and LP-HF males $(+26 \% ; P<0.05)$ in relation to their SC controls (Fig. 6), whereas this outcome was perceived exclusively in LP-HF females $(+25 \% ; P<0 \cdot 05)$. A significant three-factor interaction was also detected in relation to this parameter $(P<0.00001$; three-way ANOVA), suggesting that the postweaning HF diet amplified the effects of fetal programming and this interaction was enhanced in males.

\section{Discussion}

The present findings showed that protein restriction throughout gestation and the first half of lactation caused a significant decrease in hepatocyte number and a higher rate of hepatic steatosis in 6-month-old rats. A post-weaning HF diet maximised these outbreaks from fetal programming in both sexes, but, as a single stimulus, the HF diet exhibited these effects upon NP-HF males exclusively.

First, it is important to highlight that although the addition of condensed milk and shortening in the SC dilute out the other nutrients, none of the effects of the HF diet can be attributed to this fact since the reduction in protein content does not turn the HF diet into an LP diet. The HF diet contains $15 \%$ protein, whereas the recommendation for an adult rodent is $14 \%$. As far as micronutrients are concerned, the content of vitamins and minerals in the SC is much higher than the recommendation and thereby even if other components are added to make the HF diet, the amount falls within the normal range. Furthermore, no signs of micronutrient deficiency were observed during the experiment ${ }^{19}$.
The consumption of energy-rich diets, characterised by an increased amount of lipids, appeared as a major factor in the development of overweight as previous studies have successfully put forward ${ }^{28,29}$. In the present study, LP-HF groups showed a delayed response to this adverse stimulus on body mass probably because LP pups were subjected to protein restriction during lactation, which made these animals more resistant to weight gain even if they are weaned onto an HF diet, mainly in males ${ }^{30}$. Moreover, sexual dimorphism is attributed to the paramount influence that fetal programming exerts upon males. As evidence of this, modest maternal protein restriction programmes hypertension only in males. This phenomenon might reside, at least in part, in slower rates of growth during critical periods of development and the protective effect of oestrogens in females ${ }^{16,31}$.

An utterly striking feature observed in the present study was the development of hypertension as a result of either fetal programming or the HF diet in both sexes. Diet-induced obesity hypertension relies on a complex mechanism to develop. Indeed, insulin resistance plays a role, but hyperleptinaemia and the adipose tissue renin-angiotensin system appear as major contributors ${ }^{32,33}$. Furthermore, excessive adipose tissue activates the renin-angiotensin system through medullar compression, leading to chronic renal vasodilatation and an increased glomerular filtration rate, damaging nephron function and causing nephrosclerosis in the long run ${ }^{34,35}$.

In LP groups, hypertension is a great deal more dependent on a reduced nephron number at birth than on any other metabolic alteration ${ }^{36-38}$. Consequently, it is clear that an adverse post-weaning environment in the LP-HF groups intensified the detrimental effects of fetal programming on these animals and therefore they exhibited the highest values of systolic BP during the whole experiment, hyperinsulinaemia, hyperleptinaemia and excessive adipose tissue $e^{5,10,39}$. 
(a)

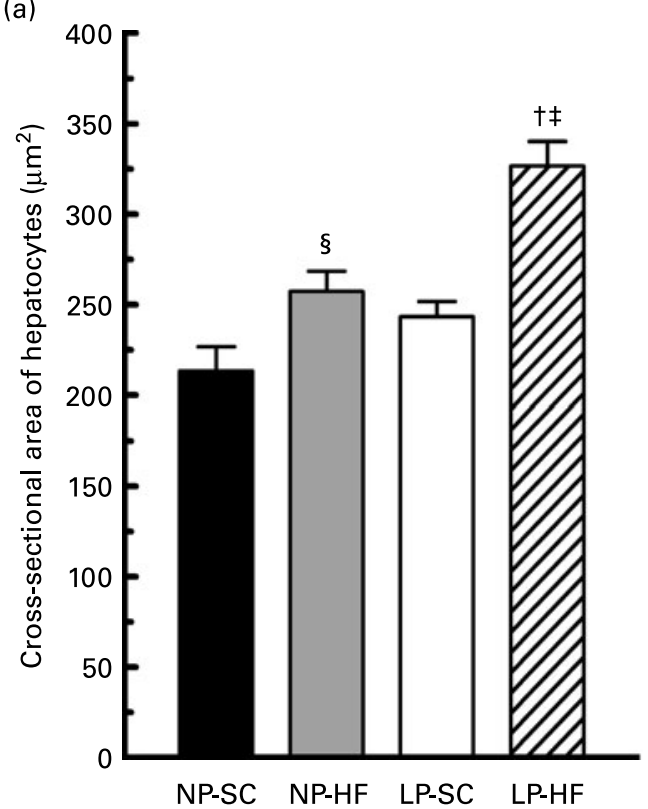

(b)

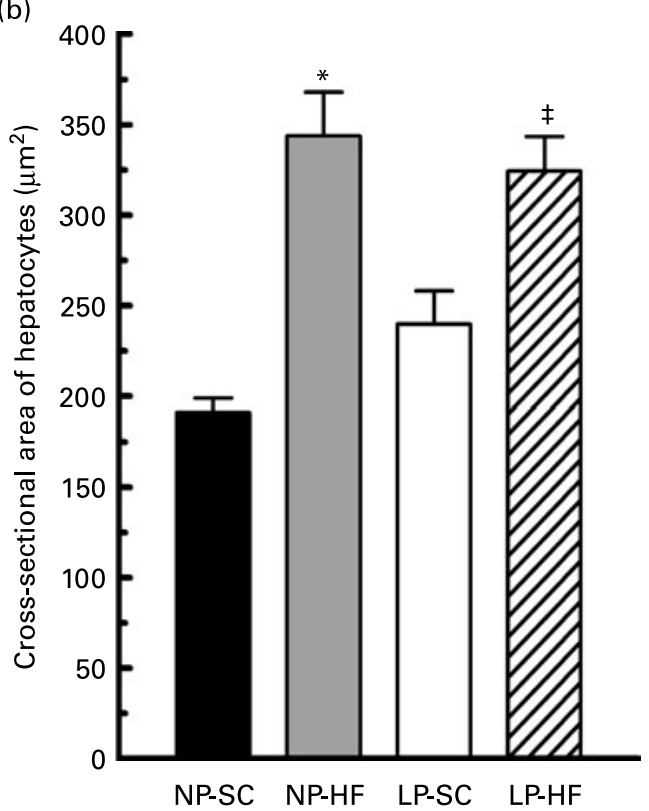

Fig. 6. Mean cross-sectional area of hepatocytes in female (a) and male (b) rats. Values are means for five rats per group, with their standard errors represented by vertical bars. NP, normal-protein; SC, standard chow; HF, high-fat chow; LP, low-protein. * Mean value was significantly different from that of the same-sex NPSC group $(P<0.0001)$. † Mean value was significantly different from that of the same-sex NP-HF group $(P<0.0001)$. $\neq$ Mean value was significantly different from that of the same-sex LP-SC group $(P<0.0001)$. $\S$ Mean value was significantly different from that of the male-matched group $(P<0.01)$. Two-way ANOVA disclosed interactions between sex and postnatal diet $(P<0.03)$ and between perinatal diet and postnatal diet $(P<0.02)$. Three-way ANOVA disclosed an interaction between sex, perinatal diet and postnatal diet $(P<0.02)$.

As for biochemical analysis, although some significant differences were observed, these cannot be taken into account given that values were within the normal range. On the other hand, liver function tests such as alanine aminotransferase and aspartate aminotransferase revealed abnormal values which comply with histological findings ${ }^{40}$. Blood lipids and hepatic enzymes were analysed on the basis that steatosis was commonplace and then impairment in lipoprotein metabolism or in liver function could be detected. The clinical significance of steatosis is generally thought to be a benign process. Subsets of patients, however, go on to develop steatohepatitis, which then progresses to fibrosis, cirrhosis, and liver failure ${ }^{41,42}$.

The stereological approach provided relevant insights into hepatic fetal programming outcomes. It is important to highlight that the point-counting approach was chosen on the basis of its better reproducibility and suitability for an accurate estimation of the degree of liver steatosis ${ }^{43}$. Despite the lack of information available on this issue, it is well established that the liver is the most impaired organ by fetal programming together with the pancreas ${ }^{2,44}$. The present study demonstrated a great reduction of hepatocyte number in 6-month-old LP-SC rats, which may be a reflection of smaller liver size at birth. Much as liver is able to regenerate, protein-restricted pups show fewer but larger hepatic lobules, which may represent an important hepatocyte number deficit since birth ${ }^{3,45}$.

Another important finding was that the HF diet maximised hepatocyte loss exclusively among males, which could be attributed to the fact that both stimuli (protein restriction and the HF diet) have a good deal more drastic consequences when applied to males ${ }^{16,31,33}$. The increase in lipid intake correlates directly with higher deposits of adipose tissue, which have been recently described as a highly active metabolic and endocrine organ ${ }^{46}$.
Excessive adipose tissue was detected in retroperitoneal and genital sites after chronic intake of the HF diet in both sexes. Hence, the HF diet is effective in raising the amount of fat pads $^{33}$, whereas perinatal nutritional constraints have been associated with a $30 \%$ reduction in fat pads ${ }^{47}$. In the present study, LP-HF rats showed smaller deposits of fat pads in comparison with NP-HF rats, which implies that maternal protein restriction overrode the influence of the HF diet on this parameter ${ }^{10}$. Additionally, females were more prone to fat accumulation in the genital region as their adipocytes exhibit a higher lipogenesis rate ${ }^{47}$.

A plausible explanation for the alteration in hepatic structure is related to an adipokine released by adipose tissue, TNF- $\alpha{ }^{48}$, which inhibits PPAR- $\alpha$ expression in the liver and thus reduces $\beta$-oxidation within hepatocytes. This outcome plays an important role on reactive oxygen species generation, which leads to apoptosis in the liver through the mitochondrial pathway. Consequently, hepatocyte number deficit programmed by maternal protein restriction may be intensified by apoptosis ${ }^{49,50}$. In addition to this, SFA are able to trigger apoptosis and reduce proliferative capacity of the liver, explaining the additional reduction in hepatocyte number displayed by LP-HF groups ${ }^{51}$.

A major point in the present study was the quantification of fat accumulation in the liver. Non-alcoholic fatty liver disease is the hepatic manifestation of the metabolic syndrome and at about $25 \%$ of the worldwide population has fallen victim to $\mathrm{it}^{52,53}$. Even though it starts as a benign process, it makes the liver more susceptible to a broad spectrum of histological damage. In fact, its progression leads to end-stage conditions such as cirrhosis and hepatocellular carcinoma and liver failure ${ }^{54}$. However, as a feature of the metabolic syndrome, steatosis has been more implicated in the worsening of glucose metabolism ${ }^{55}$. 
LP-HF groups scored the highest degree of steatosis. Maternal protein restriction causes insulin resistance through the reduction of pancreatic $\beta$-cell mass and enzymic alterations in the liver ${ }^{56,57}$. However, when subjected to the HF diet, LP-HF animals presented a disruption in the adipoinsular axis through hyperinsulinaemia and insulin resistance ${ }^{8,39}$. It is postulated that insulin resistance plays different roles in adipose tissue and liver. In the former, it stimulates lipolysis and increases NEFA supply to the liver through the portal vein, while in the latter it inhibits $\beta$-oxidation. Therefore, these animals exhibit a higher input and a decreased output of lipids, corroborating the observation of hepatic steatosis among these animals ${ }^{11,12,58}$.

Hyperleptinaemia was also detected in LP-HF groups as a result of the vast amount of adipose tissue ${ }^{5,8}$. Hyperleptinaemia impairs leptin efficacy in suppressing insulin production by the pancreas ${ }^{39,59}$. Hence, insulin resistance and hyperinsulinaemia occur and steatosis is observed through the same mechanisms described previously. After a certain degree of steatosis, hepatic insulin resistance is detected, which aggravates global insulin resistance and hepatic steatosis as well $^{58}$. Then it becomes easy to gather why LP-HF rats were the most affected group, whose values were compatible with grade 2 steatosis $(>33 \%)^{60}$.

It is also documented that SFA intensify fat accumulation within hepatocytes ${ }^{51}$. Moreover, the high content of trans fatty acids in the HF diet has also been inextricably connected to hepatic fat accumulation since this sort of fatty acid displays slower rates of oxidation ${ }^{29,61}$. Thus, the fatty acid esterification:oxidation ratio increases, which, together with hyperleptinaemia and hyperinsulinaemia, made LP-HF groups more prone to the development of hepatic steatosis ${ }^{29,62}$.

In addition to this, LP-HF groups showed the highest liver mass, albeit with fewer hepatocytes. This contrast may be explained by the greatest percentage of steatosis in combination with larger hepatocytes, provided that these groups showed the most pronounced hepatocyte area.

In summary, the present results show compelling evidence that hypertension and hepatic steatosis can be programmed in rats by severe maternal protein restriction and that this condition can be further worsened by a post-weaning HF diet. All of this serves to highlight the paramount importance of perinatal factors and the quality of the post-weaning diet when it comes to the pathogenesis of chronic diseases.

\section{Acknowledgements}

The present study was supported by the agencies CNPq (Brazilian Council of Science and Technology, http://www.cnpq. br) and FAPERJ (Rio de Janeiro State Foundation for Scientific Research, http://www.faperj.br). The authors disclose they have no financial interest or commercial sponsor for the present study. The authors thank Mrs Thatiany Marinho for technical assistance.

\section{References}

1. Langley-Evans SC \& Sculley DV (2005) Programming of hepatic antioxidant capacity and oxidative injury in the ageing rat. Mech Ageing Dev 126, 804-812.
2. Desai M, Crowther NJ, Lucas A \& Hales CN (1996) Organselective growth in the offspring of protein-restricted mothers. Br J Nutr 76, 591-603.

3. Hales CN \& Ozanne SE (2003) The dangerous road of catch-up growth. $J$ Physiol 547, 5-10.

4. Fernandez-Twinn DS \& Ozanne SE (2006) Mechanisms by which poor early growth programs type-2 diabetes, obesity and the metabolic syndrome. Physiol Behav 88, 234-243.

5. Vickers MH, Breier BH, Cutfield WS, Hofman PL \& Gluckman PD (2000) Fetal origins of hyperphagia, obesity, and hypertension and postnatal amplification by hypercaloric nutrition. Am J Physiol Endocrinol Metab 279, E83-E87.

6. McMillen IC \& Robinson JS (2005) Developmental origins of the metabolic syndrome: prediction, plasticity, and programming. Physiol Rev 85, 571-633.

7. Desai M, Byrne CD, Zhang J, Petry CJ, Lucas A \& Hales CN (1997) Programming of hepatic insulin-sensitive enzymes in offspring of rat dams fed a protein-restricted diet. Am J Physiol 272, G1083-G1090.

8. Vickers MH, Reddy S, Ikenasio BA \& Breier BH (2001) Dysregulation of the adipoinsular axis - a mechanism for the pathogenesis of hyperleptinemia and adipogenic diabetes induced by fetal programming. $J$ Endocrinol 170, 323-332.

9. Kieffer TJ \& Habener JF (2000) The adipoinsular axis: effects of leptin on pancreatic $\beta$-cells. Am J Physiol Endocrinol Metab 278, E1-E14.

10. Holness MJ \& Sugden MC (1999) Antecedent protein restriction exacerbates development of impaired insulin action after highfat feeding. Am J Physiol 276, E85-E93.

11. Koteish A \& Diehl AM (2001) Animal models of steatosis. Semin Liver Dis 21, 89-104.

12. den Boer M, Voshol PJ, Kuipers F, Havekes LM \& Romijn JA (2004) Hepatic steatosis: a mediator of the metabolic syndrome. Lessons from animal models. Arterioscler Thromb Vasc Biol 24, 644-649.

13. Akbar DH \& Kawther AH (2006) Non-alcoholic fatty liver disease and metabolic syndrome: what we know and what we don't know. Med Sci Monit 12, RA23-RA26.

14. Adams LA \& Angulo P (2005) Recent concepts in non-alcoholic fatty liver disease. Diabet Med 22, 1129-1133.

15. Aguila MB, Pinheiro AR, Parente LB \& Mandarim-de-Lacerda CA (2003) Dietary effect of different high-fat diet on rat liver stereology. Liver Int 23, 363-370.

16. Woods LL, Ingelfinger JR \& Rasch R (2005) Modest maternal protein restriction fails to program adult hypertension in female rats. Am J Physiol Regul Integr Comp Physiol 289, R1131-R1136.

17. Armitage JA, Lakasing L, Taylor PD, Balachandran AA, Jensen RI, Dekou V, Ashton N, Nyengaard JR \& Poston L (2005) Developmental programming of aortic and renal structure in offspring of rats fed fat-rich diets in pregnancy. $J$ Physiol 565, 171-184.

18. Armitage JA, Taylor PD \& Poston L (2005) Experimental models of developmental programming: consequences of exposure to an energy rich diet during development. $J$ Physiol 565, 3-8.

19. Reeves PG, Nielsen FH \& Fahey GC Jr (1993) AIN-93 purified diets for laboratory rodents: final report of the American Institute of Nutrition ad hoc writing committee on the reformulation of the AIN-76A rodent diet. J Nutr 123, 1939-1951.

20. Langley-Evans SC, Gardner DS \& Jackson AA (1996) Maternal protein restriction influences the programming of the rat hypothalamic-pituitary-adrenal axis. J Nutr 126, 1578-1585.

21. Wainwright PE (1998) Issues of design and analysis relating to the use of multiparous species in developmental nutritional studies. J Nutr 128, 661-663.

22. Quinn R (2005) Comparing rat's to human's age: how old is my rat in people years? Nutrition 21, 775-777.

23. Aoyama T, Fukui K, Takamatsu K, Hashimoto Y \& Yamamoto $\mathrm{T}$ (2000) Soy protein isolate and its hydrolysate reduce body fat 
of dietary obese rats and genetically obese mice (yellow KK). Nutrition 16, 349-354.

24. Yin FCP, Spurgeon HA, Rakusan K, Weisfeldt ML \& Lakatta EG (1982) Use of tibial length to quantify cardiac hypertrophy: application in the ageing rat. Am J Physiol 243, H941-H947.

25. Friedewald WT, Levy RI \& Fredrickson DS (1972) Estimation of the concentration of low-density lipoprotein cholesterol in plasma, without use of the preparative ultracentrifuge. Clin Chem 18, 499-502.

26. Scherle W (1970) A simple method for volumetry of organs in quantitative stereology. Mikroskopie 26, 57-60.

27. Sterio DC (1984) The unbiased estimation of number and sizes of arbitrary particles using the disector. J Microsc 134, 127-136.

28. Coatmellec-Taglioni G, Dausse JP, Ribiere C \& Giudicelli Y (2000) Hypertension in cafeteria-fed rats: alterations in renal $\alpha 2$-adrenoceptor subtypes. Am J Hypertens 13, 529-534.

29. Colandré M, Diez R \& Bernal C (2003) Metabolic effects of trans fatty acids on an experimental dietary model. $\mathrm{Br} J$ Nutr 89, 631-638.

30. Ozanne SE, Lewis R, Jennings BJ \& Hales CN (2004) Early programming of weight gain in mice prevents the induction of obesity by a highly palatable diet. Clin Sci (Lond) 106, 141-145.

31. Rich-Edwards J, Stampfer M, Manson J, Rosner B, Hankinson S, Colditz G, Willett W \& Hennekens C (1997) Birth weight and risk of cardiovascular disease in a cohort of women followed up since 1976. Br Med J 315, 396-400.

32. Dobrian AD, Davies MJ, Prewitt RL \& Lauterio TJ (2000) Development of hypertension in a rat model of diet-induced obesity. Hypertension 35, 1009-1015.

33. Coatmellec-Taglioni G, Dausse JP, Giudicelli Y \& Ribiere C (2003) Sexual dimorphism in cafeteria diet-induced hypertension is associated with gender-related difference in renal leptin receptor down-regulation. J Pharmacol Exp Ther 305, 362-367.

34. Hall J, Hildebrandt D \& Kuo J (2001) Obesity hypertension: role of leptin and sympathetic nervous system. Am J Hypert 14, 103S-115S

35. Rahmouni K, Morgan DA, Morgan GM, Mark AL \& Haynes WG (2005) Role of selective leptin resistance in diet-induced obesity hypertension. Diabetes 54, 2012-2018.

36. Almeida JR \& Mandarim-de-Lacerda CA (2005) Maternal gestational protein-calorie restriction decreases the number of glomeruli and causes glomerular hypertrophy in adult hypertensive rats. Am J Obstet Gynecol 192, 945-951.

37. Pires KMP, Aguila MB \& Mandarim-de-Lacerda CA (2006) Early renal structure alteration in rat offspring from dams fed low protein diet. Life Sci 79, 2128-2134.

38. Woods LL, Weeks DA \& Rasch R (2004) Programming of adult blood pressure by maternal protein restriction: role of nephrogenesis. Kidney Int 65, 1339-1348.

39. Holness MJ, Fryer LG \& Sugden MC (1999) Protein restriction during early development enhances insulin responsiveness but selectively impairs sensitivity to insulin at low concentrations in white adipose tissue during a later pregnancy. $\mathrm{Br} J$ Nutr 81, 481-489.

40. Angulo P (2002) Nonalcoholic fatty liver disease. N Engl J Med 346, 1221-1231.

41. Van Steenbergen W \& Lanckmans S (1995) Liver disturbances in obesity and diabetes mellitus. Int J Obes Relat Metab Disord 19, Suppl. 3, S27-S36.

42. Paradis V, Perlemuter G, Bonvoust F, et al. (2001) High glucose and hyperinsulinemia stimulate connective tissue growth factor expression: a potential mechanism involved in progression to fibrosis in nonalcoholic steatohepatitis. Hepatology 34, 738-744.
43. Franzen LE, Ekstedt M, Kechagias S \& Bodin L (2005) Semiquantitative evaluation overestimates the degree of steatosis in liver biopsies: a comparison to stereological point counting. Mod Pathol 18, 912-916.

44. Desai M, Gayle D, Babu J \& Ross MG (2005) Permanent reduction in heart and kidney organ growth in offspring of undernourished rat dams. Am J Obstet Gynecol 193, 1224-1232.

45. McMillen IC, Adam CL \& Muhlhausler BS (2005) Early origins of obesity: programming the appetite regulatory system. $J$ Physiol 565, 9-17.

46. Kershaw EE \& Flier JS (2004) Adipose tissue as an endocrine organ. J Clin Endocrinol Metab 89, 2548-2556.

47. Rees WD, Hay SM, Cruickshank M, Reusens B, Remacle C, Antipatis C \& Grant G (2006) Maternal protein intake in the pregnant rat programs the insulin axis and body composition in the offspring. Metabolism 55, 642-649.

48. Lafontan M (2005) Fat cells: afferents and efferents messages define new approaches to treat obesity. Annu Rev Pharmacol Toxicol 45, 119-146.

49. Svegliati-Baroni G, Candelaresi C, Saccomanno S, et al. (2006) A model of insulin resistance and nonalcoholic steatohepatitis in rats: role of peroxisome proliferator-activated receptor- $\{\alpha\}$ and $n-3$ polyunsaturated fatty acid treatment on liver injury. Am J Pathol 169, 846-860.

50. Schattenberg J, Galle P \& Schuchmann M (2006) Apoptosis in liver disease. Liver Int 26, 904-911.

51. Wang D, Wei Y \& Pagliassotti M (2006) Saturated fatty acids promote endoplasmic reticulum stress and liver injury in rats with hepatic steatosis. Endocrinology 147, 943-951.

52. Brunt EM (2004) Nonalcoholic steatohepatitis. Semin Liver Dis 24, 3-20.

53. Bellentani S, Saccoccio G, Masutti F, Corce L, Brandi G, Sasso F, Cristanini G \& Tribelli C (2000) Prevalence of and risk factors for hepatic steatosis in Northern Italy. Ann Intern Med 132, 112-117.

54. Bayard M, Holt J \& Boroughs E (2006) Nonalcoholic fatty liver disease. Am Fam Physician 73, 1961-1968.

55. Marceau P, Biron S, Hould FS, Marceau S, Simard S, Thung SN \& Kral JG (1999) Liver pathology and the metabolic syndrome $\mathrm{X}$ in severe obesity. J Clin Endocrinol Metab 84, $1513-1517$

56. Garofano A, Czernichow P \& Bréant B (1997) In utero undernutrition impairs $\beta$-cell development. Diabetologia 40, 1231-1234.

57. Murphy HC, Regan G, Bogdarina IG, et al. (2003) Fetal programming of perivenous glucose uptake reveals a regulatory mechanism governing hepatic glucose output during refeeding. Diabetes 52, 1326-1332.

58. Festi D, Colecchia A, Sacco T, Bondi M, Roda E \& Marchesini G (2004) Hepatic steatosis in obese patients: clinical aspects and prognostic significance. Obes Rev 5, 27-42.

59. Breier BH, Vickers MH, Ikenasio BA, Chan KY \& Wong WP (2001) Fetal programming of appetite and obesity. Mol Cell Endocrinol 185, 73-79.

60. Brunt E, Janney C, Di Bisceglie A, Neuschwander-Tetri B \& Bacon B (1999) Nonalcoholic steatohepatitis: a proposal for grading and staging the histological lessions. Am J Gastroent 94, 2467-2474.

61. Guzman M, Klein W, del Pulgar TG \& Geelen MJ (1999) Metabolism of trans fatty acids by hepatocytes. Lipids 34, 381-386.

62. Milagro FI, Campion J \& Martinez JA (2006) Weight gain induced by high-fat feeding involves increased liver oxidative stress. Obesity 14, 1118-1123. 